Supporting information for

\title{
Long-Lasting Bioluminescence Imaging of Fibroblast Activation Protein by an Amphiphilic Block Copolymer-Based Probe
}

Yibo Zhou, ${ }^{\dagger, \#}$ Keyi Yin,,${ }^{\dagger, \#}$ Hao Dong, ${ }^{\dagger, \#}$ Sheng Yang,,${ }^{*}$, JunBin Li,,${ }^{\dagger}$ Jinqiu Luo, ${ }^{\dagger}$ Yi

$$
\mathrm{Li}^{\S}{ }^{\S} \text { and Ronghua Yang }{ }^{*}, \dagger, \uparrow
$$

†Hunan Provincial Key Laboratory of Cytochemistry, School of Chemistry and Food Engineering, Changsha University of Science and Technology, Changsha, 410114, P. R. China.

¥Key Laboratory of Chemical Biology \& Traditional Chinese Medicine Research, Ministry of Education, College of Chemistry and Chemical Engineering, Hunan Normal University, Changsha, 410081, P. R. China.

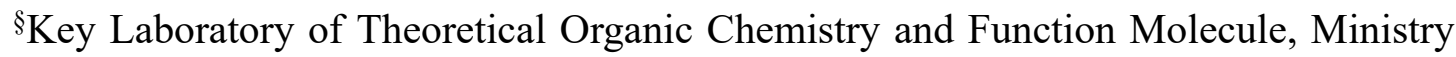
of Education, School of Chemistry and Chemical Engineering, Hunan University of Science and Technology, Xiangtan, 411201, P. R. China.

\section{Table of Contents}

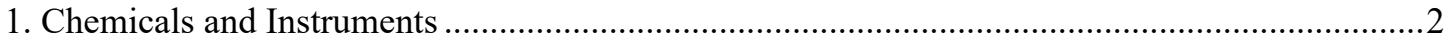

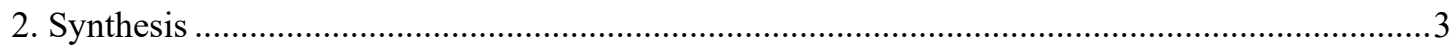

3. Critical Micelle Concentration .......................................................................................

4. Cell Incubation and Cytotoxicity Assay ..........................................................................

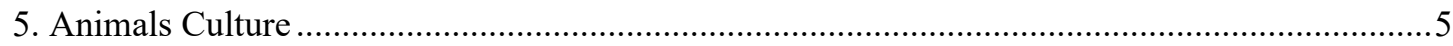

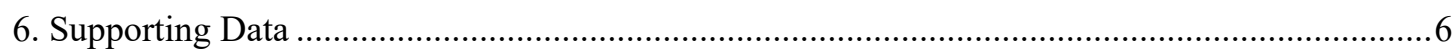

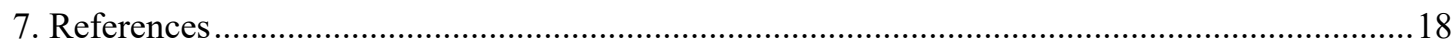




\section{Chemicals and Instruments}

Nitrine modified poly (ethylene glycol) monomethyl ether (PEG, $M \mathrm{n}=5000$ ) and tin(II) 2-ethylhexanoate $\left(\mathrm{Sn}(\mathrm{Oct})_{2}\right)$ were bought from Sigma-Aldrich (St Louis, MO). G(propargylglycine)-DRGETGPAC (alkynyl-GDRGETGPAC, purity 97.9\% from HPLC) was purchased from Nanjing Peptides Co., Ltd. (Nanjing, China). N,N,N',N",N"-pentamethyldiethylenetriamine (PMDETA, 98\%), copper(I) bromide (CuBr, 99.5\%), Nile red and D,L-lactide (99\%) were purchased from Energy Chemical (Shanghai, China). SP-13786 was bought from Glpbio (CA, USA). Luciferase were purchased from Promega (USA). D-luciferin was purchased from aladdin (Shanghai, China). Fibroblast activation protein (FAP) was bought from R\&D Systems. All the solvents such as N, N-dimethylformamide (DMF), benzene, toluene and tetrahydrofuran (THF) were dried for 24 hours with calcium hydride at room temperature and distilled under reduced pressure. Firefly luciferase-transfected cells including human breast cancer cell (MDA-MB-231 cell), human mammary epithelial cells (MCF-10A cell) and mouse breast cancer cell (4T1 cell) were provided by Professor X. B. Zhang at Hunan University (Changsha, China). BALB/c mice were obtained from Hunan Slaccas Jingda Laboratory Animal Co., Ltd, and the tumor-transplanted mice were feed at Hunan Cancer Hospital/the Affiliated Cancer Hospital of Xiangya School of Medicine, Central South University.

Fourier transforminfrared (FTIR, TENSOR 27 spectrometer), transmission electron microscope (TEM, JEOL 1200 EXII), dynamic light scattering (DLS, Malvern Zetasizer 90/ZS) and gel permeation chromatography (Waters 1515) were used to 
characterize the manufacture process of nanosensor. ${ }^{1} \mathrm{H}$ spectra were recorded with Jeol 400 spectrometer. The fluorescence emission spectra were performed on Photon Technology Intl and UV-vis absorption spectra was recorded by Shimadzu UV-2700 (Kyoto, Japan). The bioluminescence images were obtained via an IVIS Lumina III Imaging System (PerkinElmer, U.S.A.). All the western blot experiments were carried by Well Biosciences Co., Ltd in Changsha.

\section{Synthesis}

The synthesis of amphiphilic block copolymers was according to Scheme S2. ${ }^{1,2}$ Firstly, PEG-GDRGETGPAC-NH2 $\mathrm{N}_{2}$ was prepared by click reaction between azide group of PEG-N $\mathrm{N}_{3}$ and alkynyl of peptide. PEG-N $\mathrm{P}_{3}(0.3 \mathrm{~g}, 0.06 \mathrm{mmol})$, peptidyl-GDRGETGPAC (60 mg, $0.06 \mathrm{mmol})$, DMF (3 mL), and PMDETA (31 mg, $0.18 \mathrm{mmol}$ ) were added to the Schlenk flask. The mixture was frozen into solid with liquid nitrogen, then $\mathrm{CuBr}(26 \mathrm{mg}, 0.18 \mathrm{mmol})$ was added and react for $24 \mathrm{~h}$ at $40{ }^{\circ} \mathrm{C}$ under the protection of $\mathrm{N}_{2}$. The crude product was collected by precipitating the reactant into cold diethyl ether, then the product was redissolved in water and dialyzed against distilled water for 3 days with dialysis bag (MWCO: $3000 \mathrm{Da}$ ). At last, the PEG-GDRGETGPAC-NH $\mathrm{NH}_{2}$ was obtained as a solid powder after lyophilization (187.6 mg, Yield: 52.1\%).

Next, amphiphilic block copolymers was synthesized by ring-opening polymerization with PEG-GDRGETGPAC-NH $\mathrm{NH}_{2}$ as initiator. PEG-GDRGETGPAC-NH 2 (0.12 g, $0.02 \mathrm{mmol}), \mathrm{D}$, L-lactide $(0.288 \mathrm{~g}, 2 \mathrm{mmol})$ and $\mathrm{Sn}(\mathrm{OCT})_{2}(30 \mu \mathrm{L}$ in benzene, $10 \mathrm{mg} / \mathrm{ml})$ were added to the flask containing 
anhydrous THF $(1 \mathrm{~mL})$ and anhydrous benzene $(5 \mathrm{~mL})$, then mixture was freeze-dried to remove the water. After that, anhydrous THF $(4 \mathrm{~mL})$ was added and the mixture was stirred at $80^{\circ} \mathrm{C}$ for $18 \mathrm{~h}$. The residue was treated with cold diethyl ether to obtain the raw product, and the final product, PEG-GDRGETGPAC-PDLLA was obtained by desiccation. (91.3 mg, Yield: 51.4\%)

\section{Critical Micelle Concentration}

The critical micelle concentration (CMC) of the block copolymer was measured by a fluorescent probe method. ${ }^{3}$ Nile Red in THF $(0.1 \mathrm{mM}, 3 \mu \mathrm{L})$ was added into centrifuge tube, then different concentrations of amphiphilic block copolymers was added after the desiccation of Nile Red. The solution was stirred for $24 \mathrm{~h}$ at room temperature, then the emission wavelength from 570 to $750 \mathrm{~nm}$ was recorded with an excitation wavelength at $550 \mathrm{~nm}$.

\section{Cell Incubation and Cytotoxicity Assay}

Fluc-transfected MDA-MB-231 cells, fluc-transfected 4T1 cells and fluc-transfected MCF-10A were cultured with Dulbecco's modified Eagle's medium (DMEM, GIBCO) at $37{ }^{\circ} \mathrm{C}$ in humidified air containing $5 \% \mathrm{CO}_{2}$. The cellular cytotoxicity of PABC and SP-13786 toward fluc-transfected MDA-MB-231 cells was evaluated by MTT assay. The cells $\left(1 \times 10^{5}\right)$ were seeded into a 96-well plate with DMEM $(100 \mu \mathrm{L})$ medium, then the cells were cultured at $37{ }^{\circ} \mathrm{C}$ in incubator. After incubation for $24 \mathrm{~h}$, the medium was removed and different concentrations of PABC and SP-13786 were added for incubation for another $24 \mathrm{~h}$. Then the cell culture 
medium was removed and washed with PBS for three times. Subsequently, MTT (100 $\mu \mathrm{L})$ was added into plate and incubated for $4 \mathrm{~h}$ in cell incubator, DMSO (150 $\mu \mathrm{L}$ well $^{-1}$ ) was added and shaken for min. The absorbance of each well was recorded with Tecan microplate (ELISA) reader. All the experiments were repeated for three times.

\section{Animals Culture}

Athymic BALB/c nude mice (Seven-week old, female, 19 23 g) were maintained under pathogen-free conditions after being purchased from Hunan Slaccas Jingda Laboratory Animal Co., Ltd. Five days later, firefly luciferase-transfected 4T1 cells and Panc02-H7 cells $\left(2 \times 10^{6}\right.$, in $100 \mu \mathrm{L}$ PBS buffer $)$ were implanted subcutaneously under the right thigh region for each mouse when they acclimatized themselves. Then all the animals were supplied freely with irradiated feed and sterile water. About two weeks later, the tumor xenografts mice were obtained for in vivo imaging when the tumor volume reached about $2 \mathrm{~cm}^{3}$.

The tumor-transplanted mice were injected with different vehicle and placed in gas-anesthesia box (MIDMARK Matrx VMR) configured with isoflurane as anaesthetic, then the anesthetic gas was aerated (isoflurane gas $(2.0 \mathrm{~mL} / \mathrm{min})$ mixed with oxygen $(1.0 \mathrm{~mL} / \mathrm{min}))$ and the animal was anesthetized. About $1 \mathrm{~min}$ later, the head of anesthetized mice was placed in anaesthetic mask for imaging. For the imaging software, the pattern of luminescence was selected and the default settings were used for further experiment (exposure time was $1 \mathrm{~s}$, binning was $8, \mathrm{f} /$ stop was 1 , excitation filter was blocked and emission filter was opened). At last, the button of Acquire was clicked to obtain the luminescent images, then the mice were removed 
from machine and imaged at next point-in-time. Additionally, the mice were anesthetized and imaged at different point of time $(0.5,1,1.5,2,3,4$ and $5 \mathrm{~h})$. Meanwhile, all the mice were alive and in good condition after experiment.

\section{Supporting Data}

Scheme S1. The Construction of Amphiphilic Block Copolymer-Based Probe (PABC).

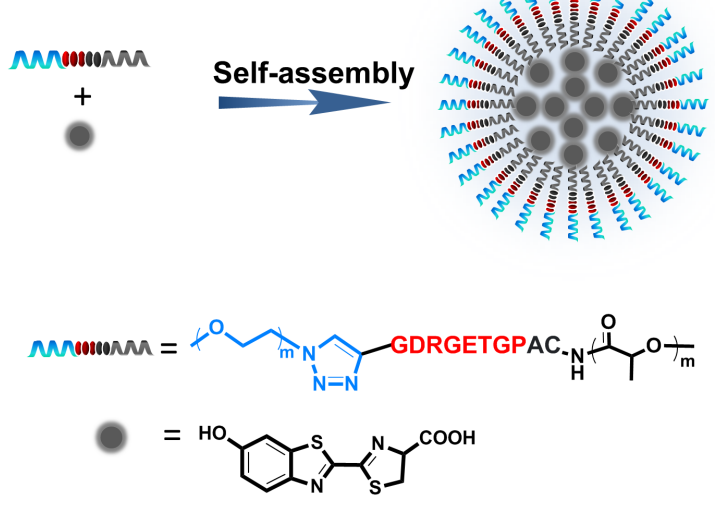

Scheme S2. Synthesis of Amphiphilic Block Copolymers.

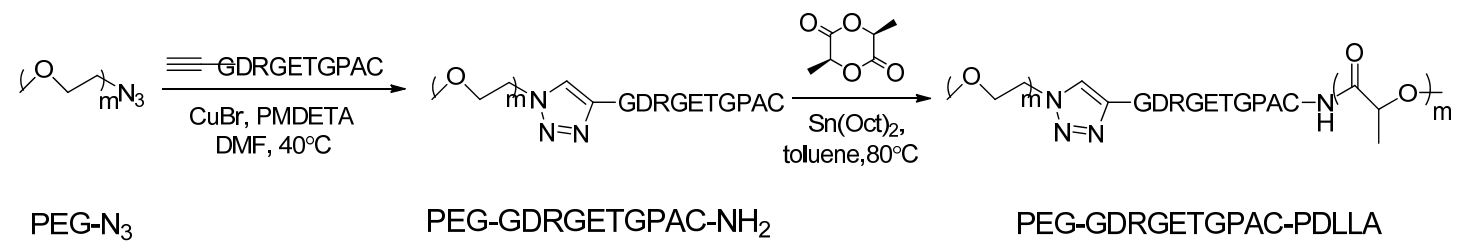




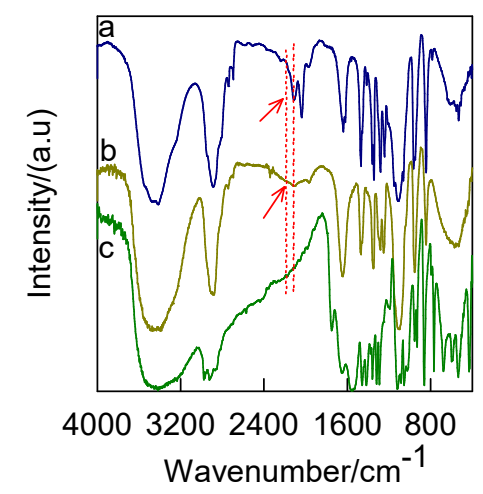

Figure S1. FTIR spectra of PEG-N ${ }_{3}$ (a), PEG-GDRGETGPAC-NH $\mathrm{N}_{2}$ (b) and PEG-GDRGETGPAC-PDLLA (c).

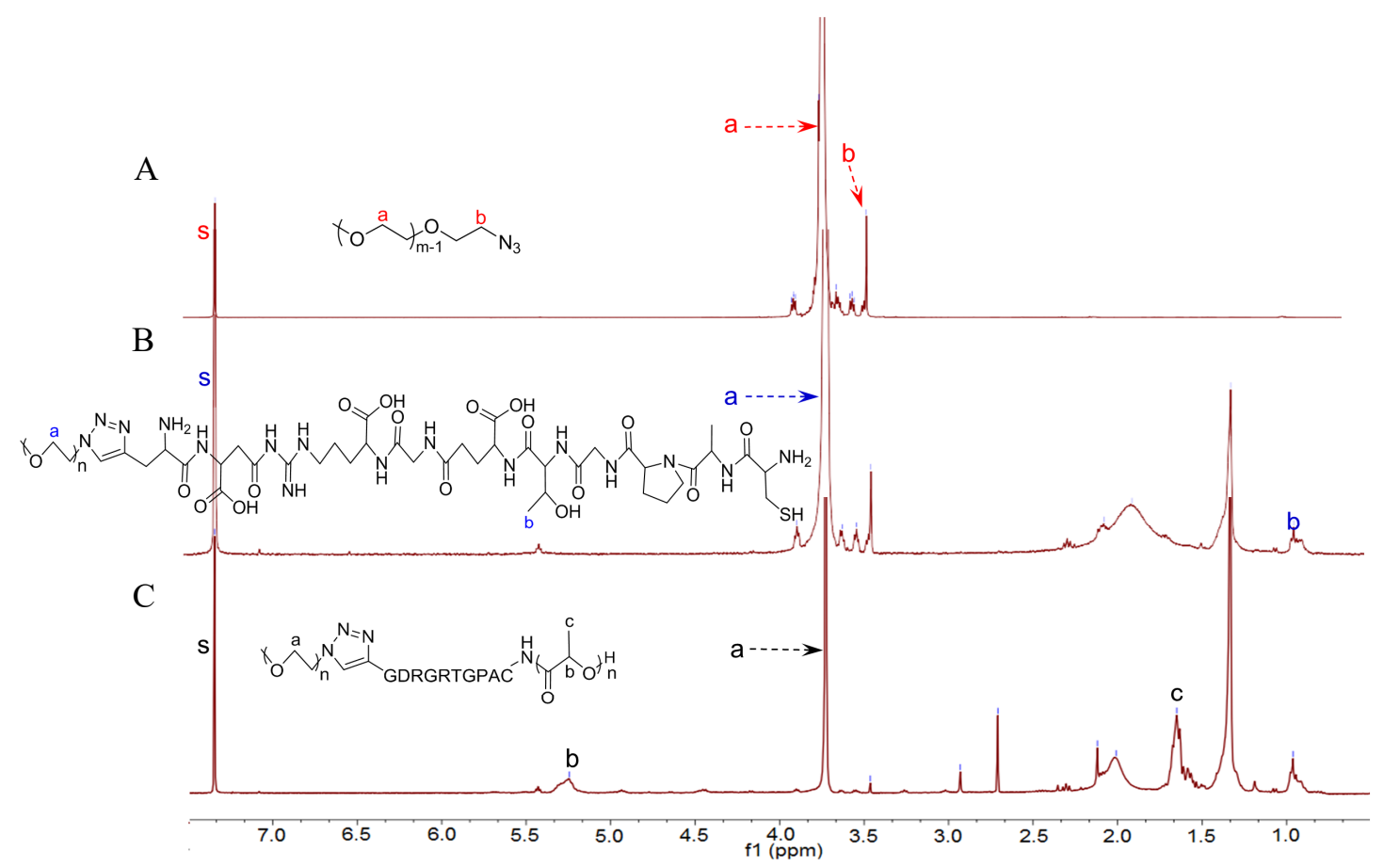

Figure S2. ${ }^{1} \mathrm{H}$ NMR spectra of (A) PEG-N 3 , (B) PEG-GDRGETGPAC-NH $\mathrm{N}_{2}$ and (C) PEG-GDRGETGPAC-PDLLA in $\mathrm{CDCl}_{3}$. 

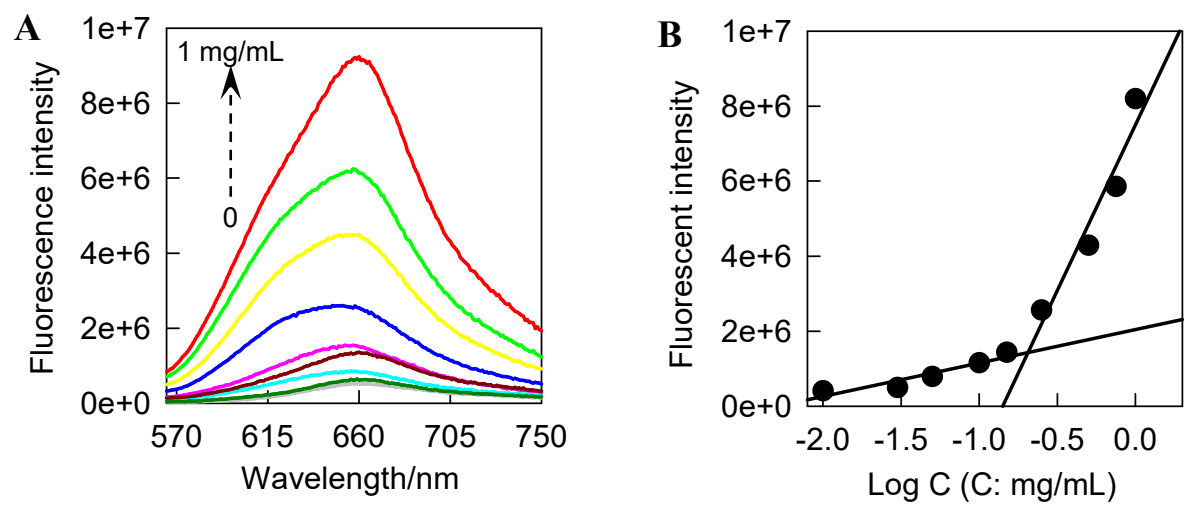

Figure S3. (A) Fluorescence emission spectra of Nile Red in phosphate buffer (20 $\mathrm{mM})$ containing different concentrations of polymer $(0.01,0.03,0.05,0.1,0.15,0.25$, $0.5,0.75$ and $1 \mathrm{mg} / \mathrm{mL}$ ), $\lambda_{\mathrm{ex}}=550 \mathrm{~nm}$. (B) The relevant emission intensity at $642 \mathrm{~nm}$ versus the log of concentration of polymer.

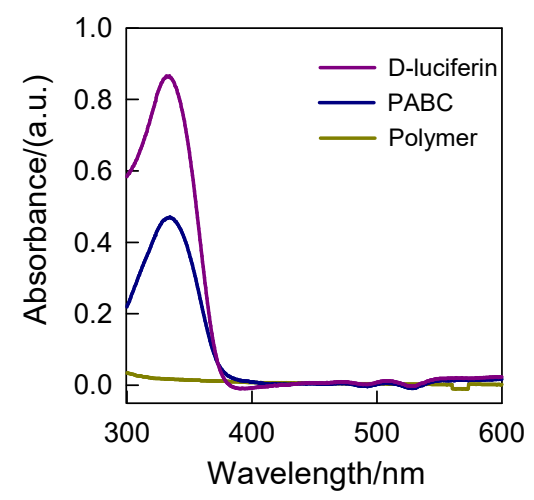

Figure S4. UV-vis absorption spectra of free D-luciferin $(40 \mu \mathrm{M})$, PABC $(0.5 \mathrm{mg} / \mathrm{mL})$ and polymer $(0.5 \mathrm{mg} / \mathrm{mL})$ in phosphate buffer $(20 \mathrm{mM})$. 


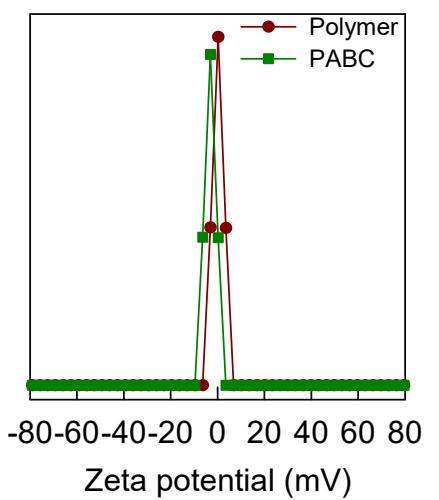

Figure S5. Zeta potential of activated polymer and PABC in phosphate buffer (20 $\mathrm{mM})$.
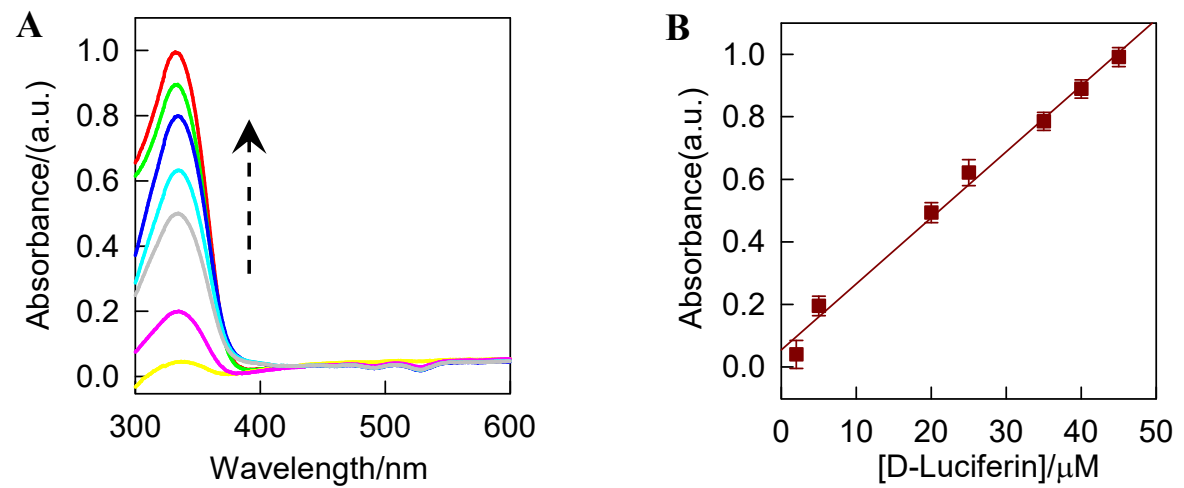

Figure S6. (A) UV-vis absorption spectra of different concentrations of free D-luciferin in phosphate buffer $(20 \mathrm{mM})$. The arrows indicate the intensity changes with increase of D-luciferin concentrations $(1,5,20,25,35,40$ and $45 \mu \mathrm{M})$. (B) The relevant absorption intensity at $330 \mathrm{~nm}$ versus the concentration of D-luciferin. 

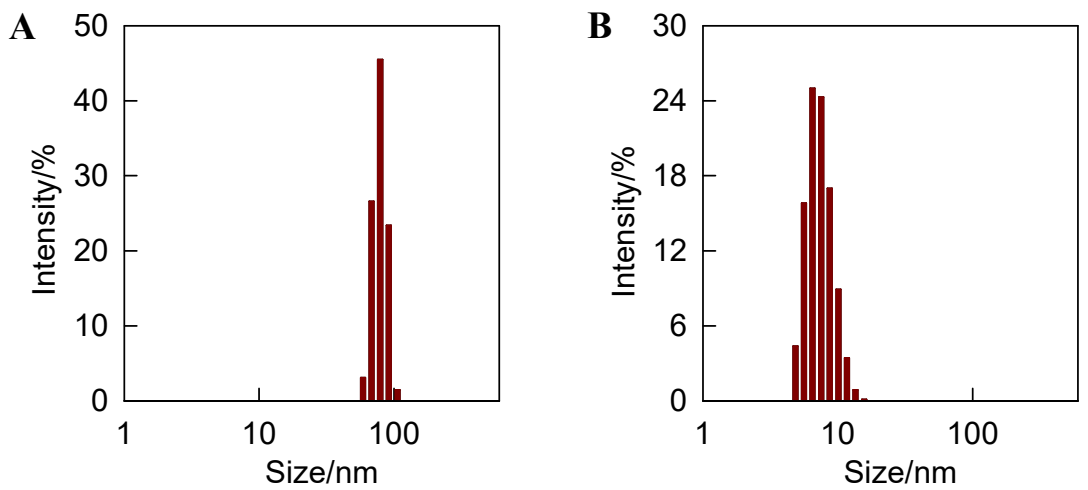

C

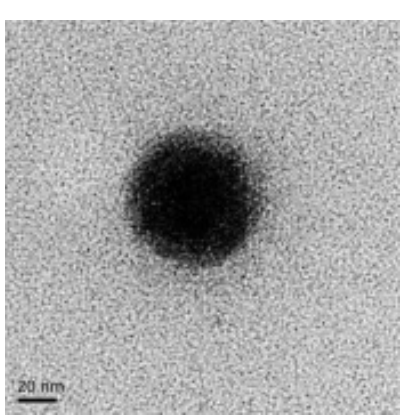

$\mathrm{D}$

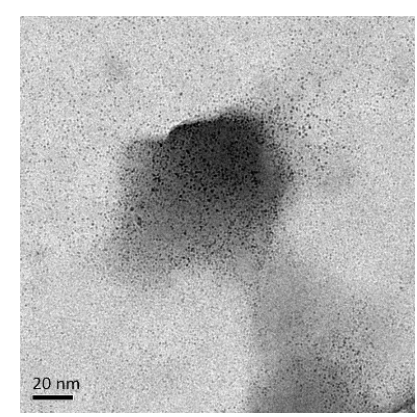

Figure S7. The DLS and TEM images of PABC before $(\mathrm{A}, \mathrm{C})$ and after $(\mathrm{B}, \mathrm{D})$ treated with FAP (100 ng/mL), scale bars: $20 \mathrm{~nm}$. 
A

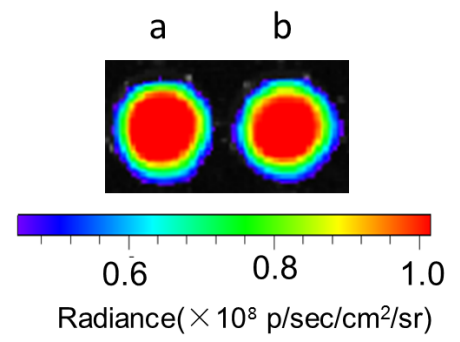

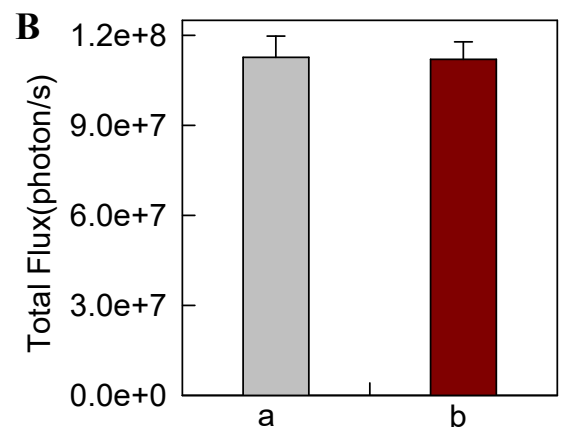

Figure S8. (A) Bioluminescence images of the total photo flux of D-luciferin $(9 \mu \mathrm{M})$ in the absence (a) and presence (b) of FAP $(100 \mathrm{ng} / \mathrm{mL})$ in phosphate buffer $(20 \mathrm{mM})$ containing luciferase $(10 \mu \mathrm{g} / \mathrm{mL})$, ATP $(2 \mathrm{mM})$ and $\mathrm{Mg}^{2+}(10 \mathrm{mM})$. (B) Quantification of the total photon flux for A. The results are presented as mean: standard deviation $(n=3)$.

A

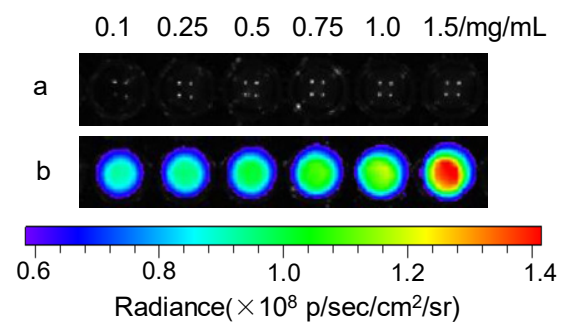

B

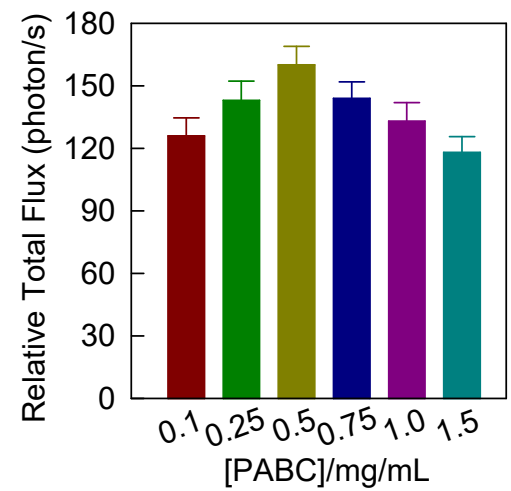

Figure S9. (A) Bioluminescence images of the total photo flux of different concentration of $\operatorname{PABC}(0.1,0.25,0.5,0.75,1.0$ and $1.5 \mathrm{mg} / \mathrm{mL})$ in the absence (a) and presence (b) of FAP (100 $\mathrm{ng} / \mathrm{mL})$ in phosphate buffer $(20 \mathrm{mM})$ containing luciferase $(10 \mu \mathrm{g} / \mathrm{mL})$, ATP $(2 \mathrm{mM})$ and $\mathrm{Mg}^{2+}(10 \mathrm{mM})$. (B) Relative total photo flux change of different concentration of PABC $(0.1,0.25,0.5,0.75,1.0$ and $1.5 \mathrm{mg} / \mathrm{mL})$ with FAP $(100 \mathrm{ng} / \mathrm{mL})$. The results are presented as mean: standard deviation $(\mathrm{n}=3)$. 

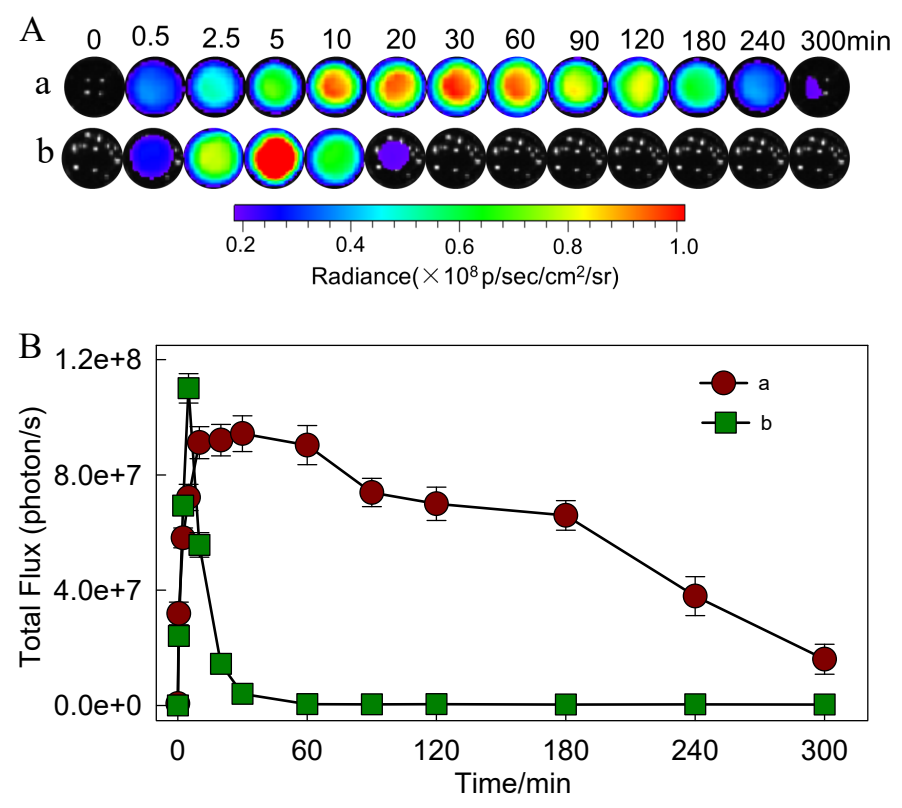

Figure S10. (A) Time-course bioluminescence images of PABC (a, $0.5 \mathrm{mg} / \mathrm{mL}$ ) and D-luciferin $(\mathrm{b}, 9 \mu \mathrm{M})$ after treatment with FAP $(100 \mathrm{ng} / \mathrm{mL})$ in phosphate buffer $(20$ $\mathrm{mM})$ containing luciferase $(10 \mu \mathrm{g} / \mathrm{mL})$, ATP $(2 \mathrm{mM})$ and $\mathrm{Mg}^{2+}(10 \mathrm{mM})$. (B) Quantification of the total photon flux for A. The results are presented as mean: standard deviation $(\mathrm{n}=3)$. 


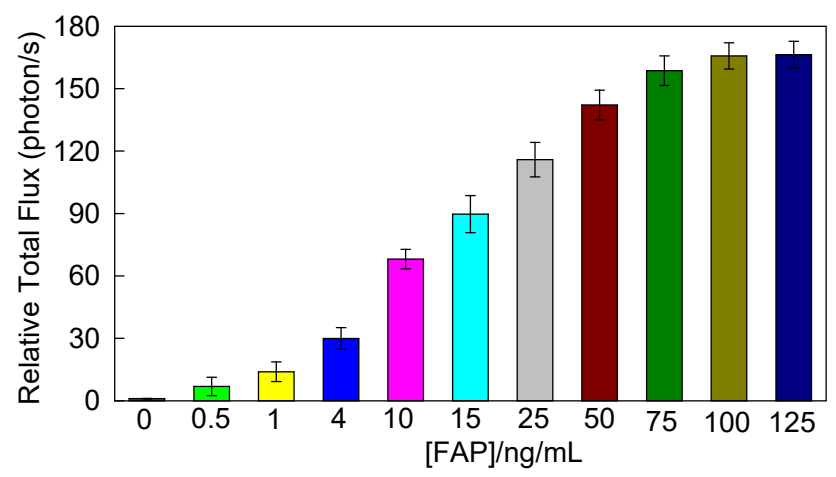

Figure S11. Relative total photo flux change of PABC $(0.5 \mathrm{mg} / \mathrm{mL})$ with different concentration of FAP.

A
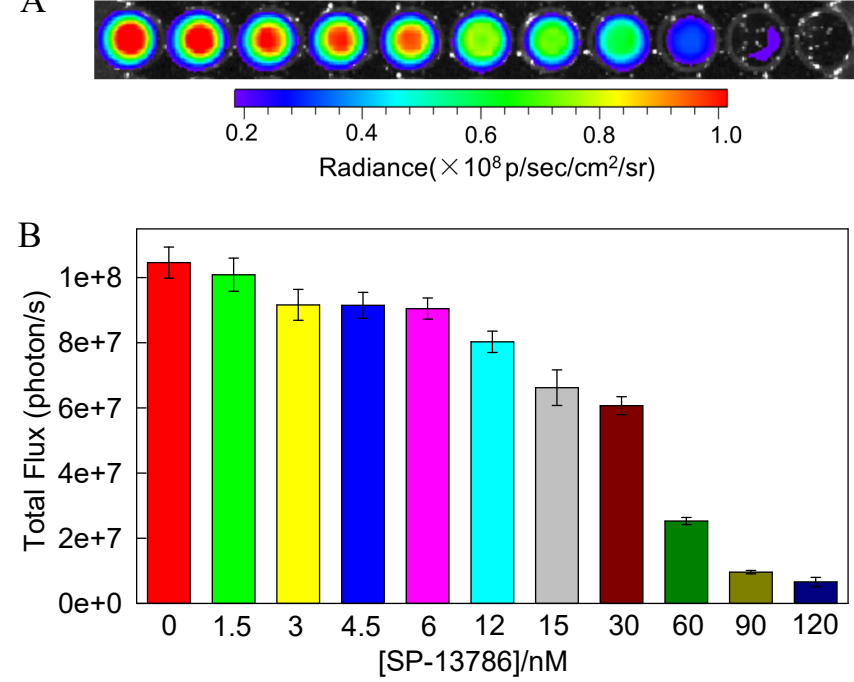

Figure S12. (A) Bioluminescence images of PABC $(0.5 \mathrm{mg} / \mathrm{mL})$ incubated with FAP $(100 \mathrm{ng} / \mathrm{mL})$ pretreated with different concentrations of SP-13786 $(0,1.5,3,4.5,6,12$, $15,30,60,90$ and $120 \mathrm{nM})$ in phosphate buffer $(20 \mathrm{mM})$ containing luciferase $(10$ $\mu \mathrm{g} / \mathrm{mL})$, ATP $(2 \mathrm{mM})$ and $\mathrm{Mg}^{2+}(10 \mathrm{mM})$. (B) Quantification of the total photon flux for $\mathrm{A}$. The results are presented as mean: standard deviation $(n=3)$. 
A

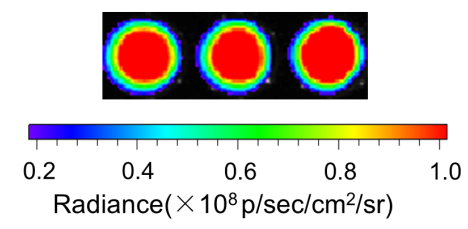

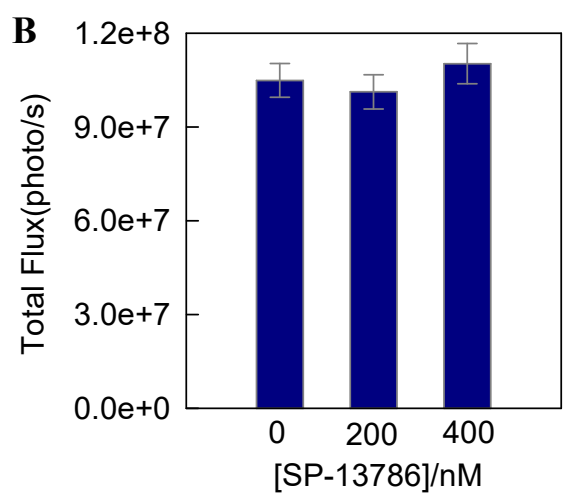

Figure S13. (A) Bioluminescence images of D-luciferin $(9 \mu \mathrm{M})$ by titration with different concentrations of SP-13786 $(0,200$ and $400 \mathrm{nM})$ in phosphate buffer (20 $\mathrm{mM})$ containing luciferase $(10 \mu \mathrm{g} / \mathrm{mL})$, ATP $(2 \mathrm{mM})$ and $\mathrm{Mg}^{2+}(10 \mathrm{mM})$. (B) Quantification of the total photon flux for A. The results are presented as mean: standard deviation $(n=3)$.

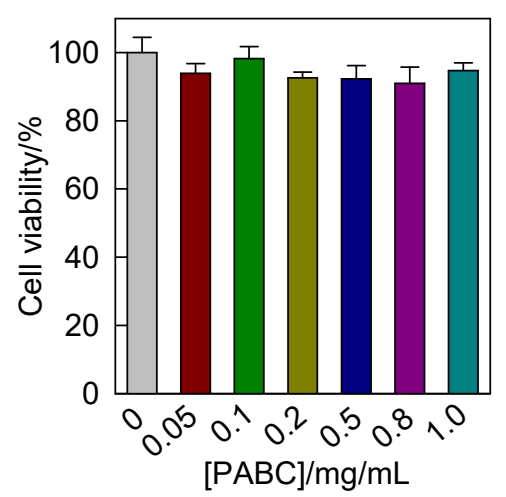

Figure S14. Cell viability study of fluc-transfected MDA-MB-231 cells incubated with different concentrations of PABC. 


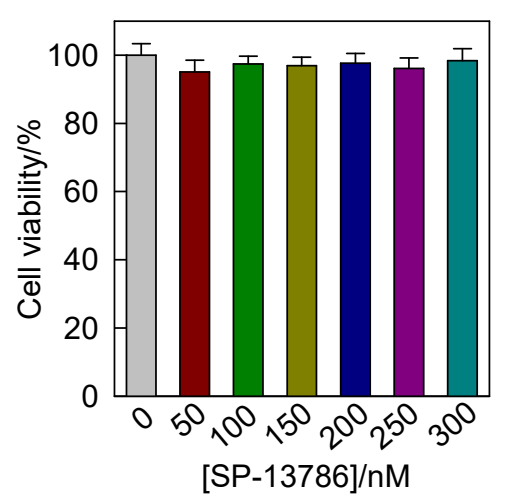

Figure S15. Cell viability study of fluc-transfected MDA-MB-231 cells incubated with different concentrations of SP-13786. 

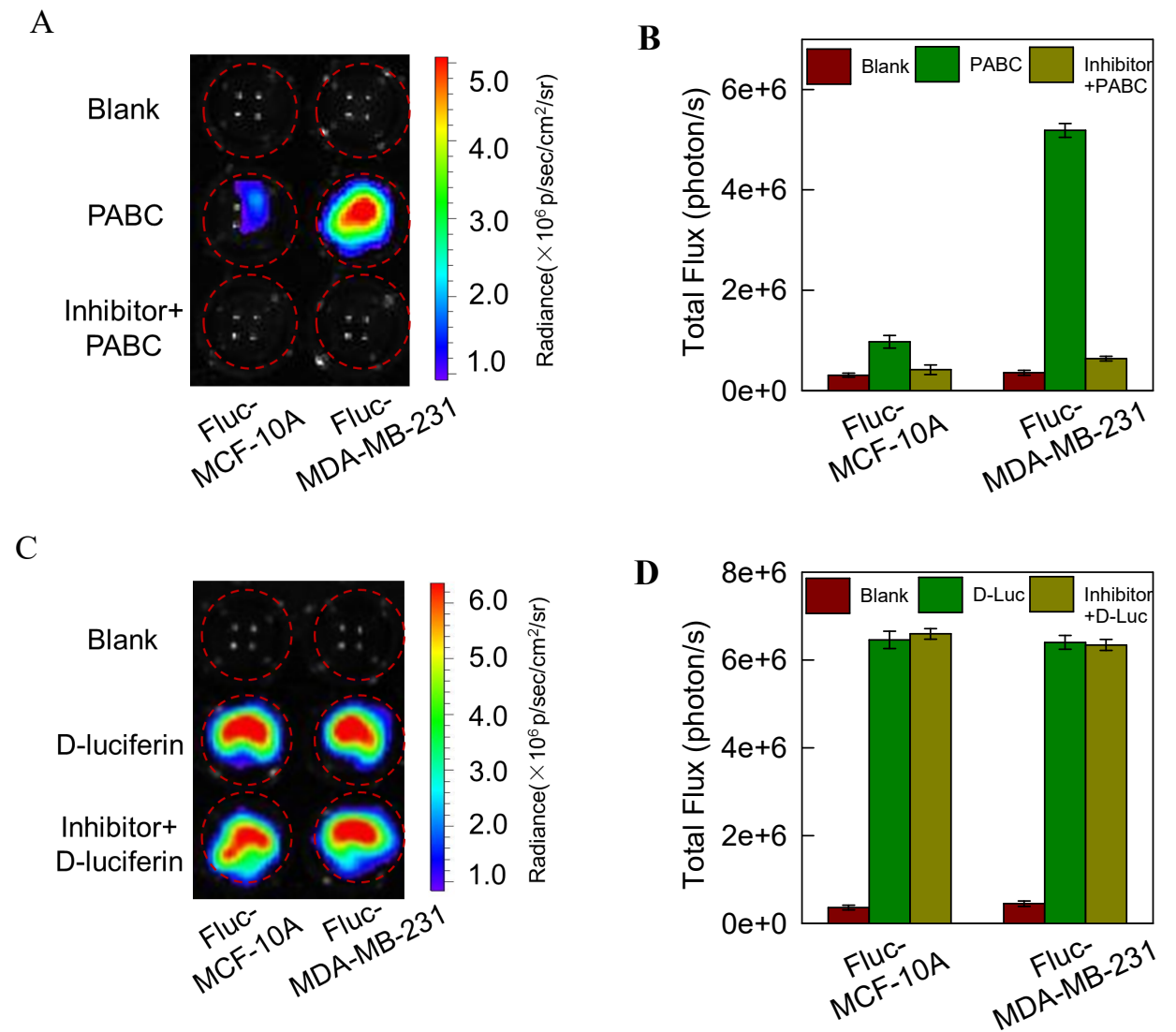

Figure S16. (A) Bioluminescence images of fluc-transfected MCF-10A and MDA-MB-231 cells incubated with PABC $(0.5 \mathrm{mg} / \mathrm{mL})$ or PABC $(0.5 \mathrm{mg} / \mathrm{mL})$ with SP-13786 (100 nM) for $90 \mathrm{~min}$ in serum-free culture medium at $37{ }^{\circ} \mathrm{C}$. (B) Quantification of the total flux (photon/s) in A. (C) Bioluminescence images of fluc-transfected MCF-10A and MDA-MB-231 cells incubated with D-luciferin $(9 \mu \mathrm{M})$ or D-luciferin $(9 \mu \mathrm{M})$ with SP-13786 $(100 \mathrm{nM})$ for $10 \mathrm{~min}$ in serum-free culture medium at $37{ }^{\circ} \mathrm{C}$. (D) Quantification of the total flux (photon/s) in C. 

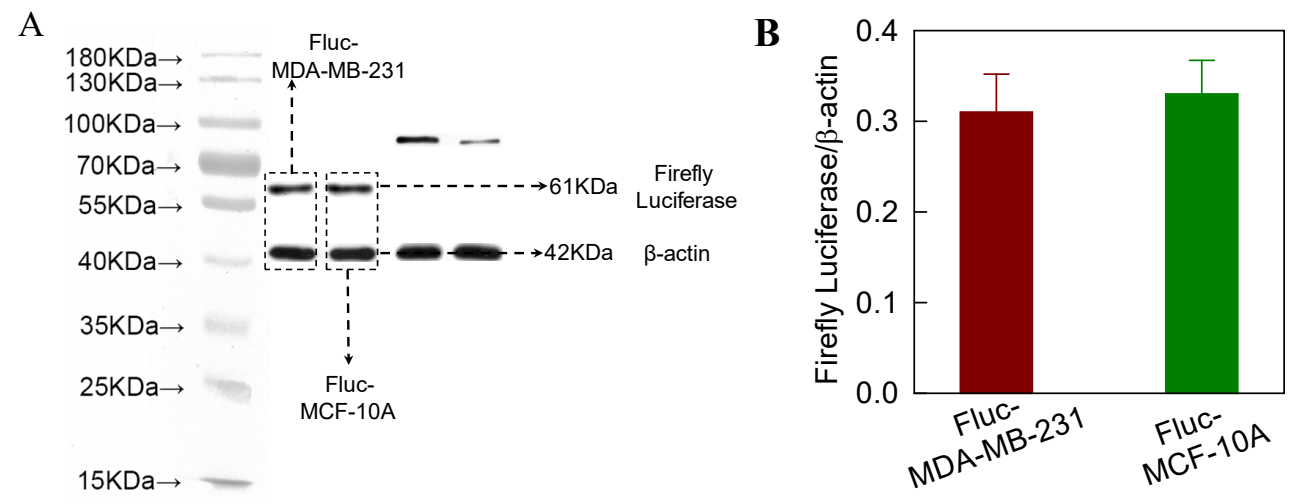

Figure S17. (A) Western blot analysis of firefly luciferase and $\beta$-actin (internal reference) within fluc-transfected MDA-MB-231 and MCF-10A cells. (B) The corresponding firefly luciferase expression of (A). Error bars indicate s.d. $(\mathrm{n}=3)$.

A

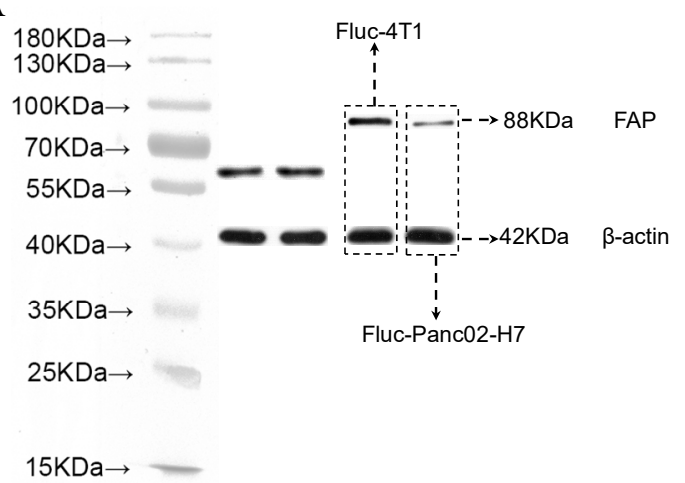

B

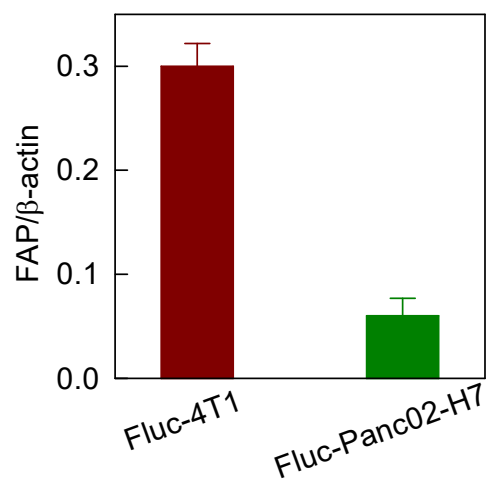

Figure S18. (A) Western blot analysis of FAP and $\beta$-actin (internal reference) within fluc-transfected 4T1 and Panc02-H7 cells. (B) The corresponding FAP expression of (A). Error bars indicate s.d. $(\mathrm{n}=3)$. 
A

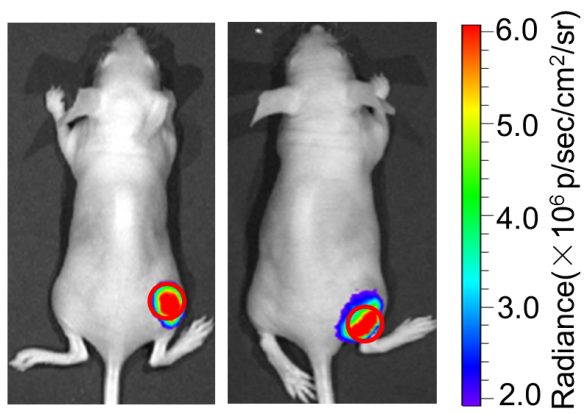

B

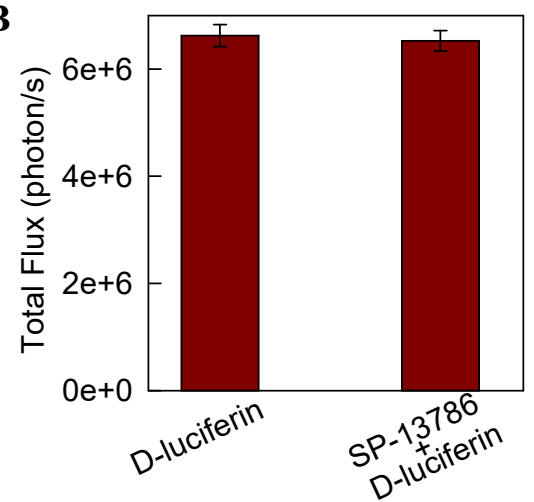

Figure S19. (A) Bioluminescence images of fluc-transfected 4T1 tumor-bearing mice under different conditions: injection of D-luciferin $(9 \mu \mathrm{M})$; injection of SP-13786 (120 nM) followed by D-luciferin $(9 \mu \mathrm{M})$. (B) Quantified total photon output (photon/s) in A.

\section{References}

(1) Ke, W. D.; Li, J. J.; Zhao, K. J.; Zha, Z. S.; Han, Y.; Wang, Y. H.; Yin, W.; Zhang, P.; Ge, Z. S. Modular Design and Facile Synthesis of Enzyme-Responsive Peptide-Linked Block Copolymers for Efficient Delivery of Doxorubicin. Biomacromolecules 2016, 17, 3268-3276.

(2) Ke, W. D.; Zha, Z. S.; Mukerabigwi, J. F.; Chen, W. J.; Wang, Y. H.; He, C. X.; Ge, Z. S. Matrix Metalloproteinase-Responsive Multifunctional Peptide-Linked Amphiphilic Block Copolymers for Intelligent Systemic Anticancer Drug Delivery. Bioconjugate Chem. 2017, 28, 2190-2198.

(3) Yan, Q.; Sang, W. $\mathrm{H}_{2} \mathrm{~S}$ Gasotransmitter-Responsive Polymer Vesicles. Chem. Sci. 2016, 7, 2100-2105. 